06.1

\title{
Композитные пористые стеклянные мембраны, содержащие золотые наночастицы, полученные методом лазерного осаждения металла из раствора
}

\author{
() Д.В. Лебедев ${ }^{1,2}$, И.Н. Анфримова ${ }^{3}$, Т.В. Антропова ${ }^{3}$ \\ ${ }^{1}$ Санкт-Петербургский государственный университет, Санкт-Петербург, Россия \\ ${ }^{2}$ Санкт-Петербургский национальный исследовательский Академический университет им. Ж.И. Алфёрова РАН, \\ Санкт-Петербург, Россия \\ ${ }^{3}$ Институт химии силикатов им. И.В. Гребенщикова РАН, Санкт-Петербург, Россия \\ E-mail: Denis.v.lebedev@gmail.com
}

Поступило в Редакцию 4 мая 2021 г.

В окончательной редакции 13 мая 2021 г.

Принято к публикации 14 мая 2021 г.

\begin{abstract}
Разработана методика получения композитных мембран на основе пористого стекла. Внутри нанопор стеклянных мембран были сформированы золотые наночастицы, обладающие плазмонным резонансом. Средний размер полученных частиц составил 20-25 nm. Полученные мембраны являются перспективными для разработки сенсоров нового поколения и исследования влияния эффекта плазмонного резонанса на транспорт ионов внутри нанопор.
\end{abstract}

Ключевые слова: пористое стекло, золотые наночастицы, плазмонный резонанс, мембраны, лазерное излучение.

DOI: 10.21883/PJTF.2021.17.51377.18856

Благодаря развитию современных технологий в настоящее время большой интерес вызывает исследование ионного транспорта в нанопорах и наноканалах. Эти работы актуальны и имеют широкий спектр применения в различных областях науки и техники. Среди прочих можно выделить разделение смесей и получение чистых веществ $[1,2]$, преобразование энергии электрохимическими методами [3], разработку химических сенсоров [4], молекулярную биологию и физиологию клеток [5] и т.д. Разработка искусственных аналогов ионных каналов и насосов клеточных мембран на данный момент весьма актуальна [6]. Основная задача этих работ - понять принципы действия природных систем и использовать их в приложениях. Также в настоящее время активно изучается влияние электромагнитного поля и заряда на селективные свойства мембран ввиду наличия многочисленных практических приложений.

Гибридные или композитные мембраны, содержащие различные наночастицы, активно изучаются в последнее десятилетие [7,8]. Ранее было показано, что присутствие различных неорганических частиц в структуре мембраны может приводить к изменению ее транспортных и селективных свойств. С другой стороны, исследование смещения плазмонной полосы поглощения наночастиц золота при наличии в их окружении различных ионов и молекул также является очень важной задачей $[9,10]$. Таким образом, сочетание транспортных свойств наноканалов и частиц, демонстрирующих плазмонный резонанс, имеет большой потенциал для применения во многих технологиях.
Целью данного исследования является разработка методики синтеза композитных пористых мембран, содержащих золотые наночастицы внутри пор.

В качестве основы для композитных мембран были выбраны пористые стекла (ПС). Силикатные (кремнеземные) ПС представляют собой наноструктурированные материалы канального типа [11]. ПС являются термически, химически и микробиологически стабильными и имеют контролируемые структурные характеристики поверхности [12]. Образцы пористого стекла в виде плоскопараллельных полированных пластин размером $10 \times 10 \times 1.0 \mathrm{~mm}$ были изготовлены путем химического травления натриево-боросиликатного стекла с двухкаркасной структурой марки 8В-НТ [13] в водных растворах $\mathrm{HCl}$ и $\mathrm{KOH}$ последовательно с последующей промывкой в дистиллированной воде и сушкой при $120^{\circ} \mathrm{C}$ в воздушной атмосфере в соответствии с процедурой, описанной в [13]. Параметры текстуры ПС определялись адсорбционными методами [14]. Пористость ПС и средний диаметр пор составили 50\% и $25 \mathrm{~nm}$ соответственно [13]. Важно отметить, что используемые ПС-материалы являются оптически прозрачными в видимой области спектра [15].

Для формирования металлических (золотых) наночастиц внутри пор стеклянной мембраны был использован метод лазерного осаждения металлов из раствора [16]. Суть данной методики заключается в осаждении металла из раствора на поверхность диэлектрика под воздействием лазерного излучения. Схема экспериментальной установки для синтеза мембран представлена на рис. 1. 


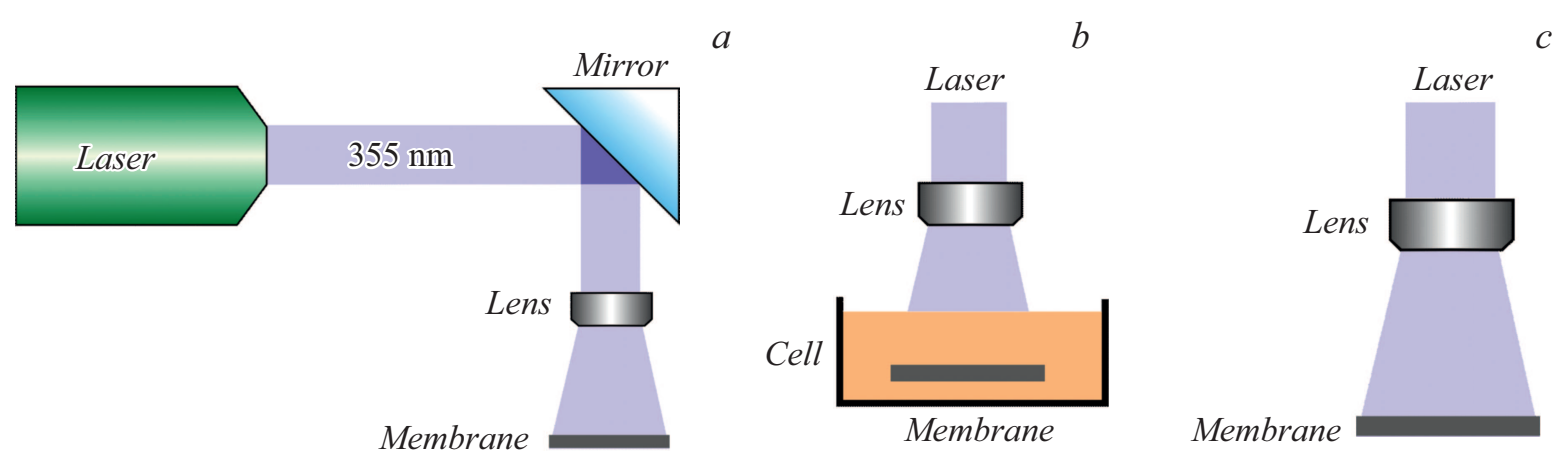

Рис. 1. $a$ - схематическое изображение установки для синтеза мембран; $b, c-$ варианты позиционирования мембраны в области лазерного излучения. Для синтеза мембран применялась схема, показанная на части $c$.

Для синтеза мембран был использован импульсный лазер с длиной волны $355 \mathrm{~nm}$ и временем импульса 20 ns. Луч лазера, отражаясь от зеркала, падает на мембрану, при этом световой пучок дефокусируется с помощью объективной линзы (фокусное расстояние $60 \mathrm{~mm}$ ). Широкий пучок света необходим для того, чтобы реализовать однородный синтез наночастиц на всей поверхности мембраны. При фокусировке луча в точку на поверхности мембраны происходил быстрый неоднородный рост частиц в области фокусировки. При этом на стекле формировался металлический осадок в виде островковой пленки золота. Такая пленка не обладает плазмонными свойствами. Кроме того, массивные частицы золота могут забивать поры мембраны, делая ее непригодной для работы. Таким образом, оптимальным является формирование на поверхности мембраны широкого однородного светового пятна.

Важным этапом при формировании мембраны является вымачивание мембраны в растворе прекурсора перед синтезом. С этой целью мембрану пропитывали раствором до эксперимента. Время пропитывания составляло от $1 \mathrm{~min}$ до $3 \mathrm{~h}$. Исследования показали, что оптимальным временем вымачивания является $30 \mathrm{~min}$. При меньших временах раствор не успевает проникать внутрь мембраны, при бо́льших мембрана насыщается раствором и дальнейшее вымачивание излишне. В качестве раствора прекурсора был использован раствор тетрахлороаурата водорода $\left(\mathrm{HAuCl}_{4}\right)$ в воде. После вымачивания мембрана подвергалась воздействию оптического излучения, в результате чего внутри пор формировались наночастицы золота. Механизм формирования частиц детально описан в литературе [17]. Изначально предполагалось, что синтез частиц будет равномерно происходить в толще мембраны при погружении последней в ячейку с рабочим раствором (рис. $1, b$ ). Однако исследования показали, что при данной конфигурации экспериментальной установки частицы формируются преимущественно в приповерхностных слоях мембраны. Это объясняется интенсивностью химических реакций и, как следствие, существенным поглощением лазерного излучения в приповерхностном слое. Для устранения этого недостатка была предложена схема облучения образца, представленная на рис. 1, c. В данном случае мембрана пропитывалась раствором прекурсора в течение $30 \mathrm{~min}$, а затем излишки раствора удалялись с поверхности ПС с помощью фильтровальной бумаги. После этого образец помещался в область лазерного луча. Таким образом, формирование наночастиц золота происходило равномерно по всей толщине мембраны.

На рис. 2, а представлено изображение скола мембраны, полученное на сканирующем электронном микроскопе (СЭМ). Видно, что золотые наночастицы распределены однородно по всей глубине мембраны.

Для исследования зависимости плазмонных свойств получаемых частиц от условий синтеза было сделано несколько образцов при разных временах и концентрациях исходного раствора. Время синтеза варьировалось от 0.5 до $15 \mathrm{~min}$, концентрации изменялись в пределах 1-25 mM. Мощность лазерного излучения составила $0.3 \mathrm{~W}$. Для каждого полученного образца был измерен спектр поглощения. На рис. 2, $b$ приведены типичные спектры поглощения для исследуемой группы образцов.

На рис. 2, $b$ отчетливо видна линия поглощения на длине волны 540-550 nm, что соответствует плазмонному резонансу золотых наночастиц размером 20-25 nm. Из полученных спектров видно, что при малых временах синтеза амплитуда линии поглощения невелика, что свидетельствует о малом количестве полученных частиц. При увеличении времени синтеза число синтезированных частиц растет, а вместе с ним увеличивается и амплитуда линии поглощения. Кроме того, можно сделать вывод, что средний размер золотых наночастиц слабо зависит от параметров синтеза. По всей видимости, это связано со средним размером пор, внутри которых происходит формирование частиц. Важно отметить, что ухудшение плазмонных свойств (уменьшение поглощения) при высоких концентрациях $(0.025 \mathrm{M})$ и длительных временах синтеза (10-15 min) может свидетельствовать о синтезе более крупных частиц, не обладающих плазмонными свойствами. С учетом структуры стеклянной матрицы (поры имеют извилистый „губкообразный характер“) вполне допустимо наличие 

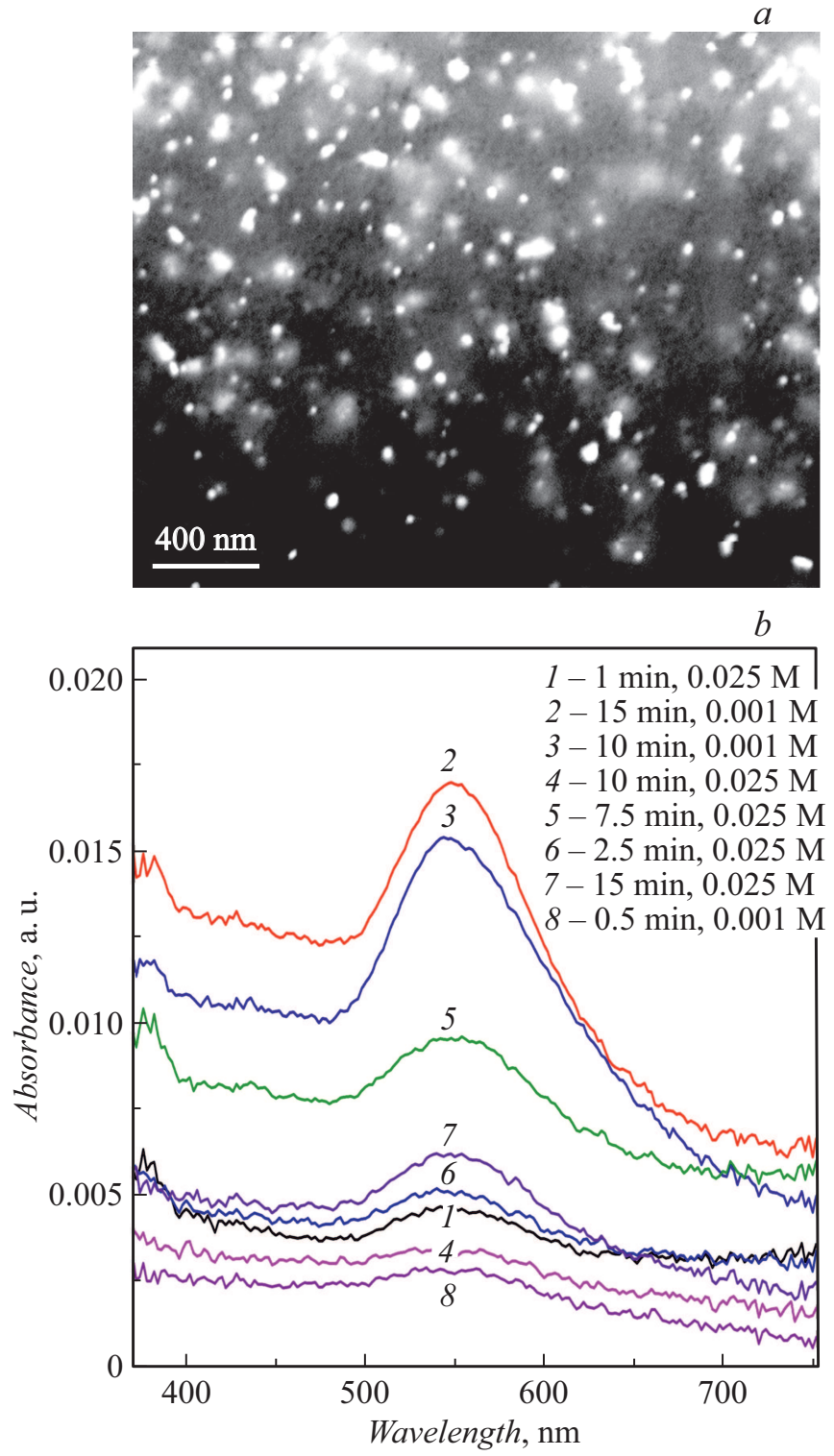

Рис. 2. $a-$ СЭМ-изображение скола композитной мембраны; $b-$ спектры поглощения композитных мембран, содержащих золотые наночастицы.

пустот больше $25 \mathrm{~nm}$ в диаметре. Таким образом, существование частиц размером более $25 \mathrm{~nm}$ возможно.

Итак, в ходе выполнения исследования была разработана методика формирования золотых наночастиц внутри пор ПС-материалов. Предложенная методика позволяет синтезировать наночастицы в толще пористой матрицы, получая таким образом композитный материал. Основное требование к матрице в данном случае - оптическая прозрачность. Был получен ряд образцов с различными условиями синтеза. Установлено, что определяющим фактором при синтезе частиц внутри нанопор являются геометрические параметры последних. Простота и надежность разработанной методики позволяют сделать вывод о перспективности применения данного подхода для создания композитных материалов.
Полученные мембраны являются перспективными для разработки сенсоров нового поколения и исследования влияния эффекта плазмонного резонанса на транспорт ионов внутри нанопор. Такие исследования можно проводить, например, анализируя фильтрационные свойства мембран под воздействием лазерного излучения на резонансной длине волны. В данном случае энергия лазерного луча будет локализоваться в виде ближнего поля вокруг наночастиц, тем самым создавая неоднородное электромагнитное поле внутри поры мембраны, которое в свою очередь может повлиять на движение заряженных ионов через мембрану.

\section{Финансирование работы}

Работа выполнена при финансовой поддержке Российского научного фонда (проект № 19-79-00095). Изготовление образцов пористого стекла и характеризация их текстуры проведены в Институте химии силикатов им. И.В. Гребенщикова РАН при поддержке Минобрнауки России (тема № AАAА-A19-119022290087-1).

\section{Конфликт интересов}

Авторы заявляют, что у них нет конфликта интересов.

\section{Список литературы}

[1] В.В. Волков, Б.В. Мчедлишвили, В.И. Ролдугин, С.С. Иванчев, А.Б. Ярославцев, Рос. нанотехнологии, 3 (11-12), 67 (2008).

[2] H. Strathmann, Ion-exchange membrane processes in water treatment. Ser. Sustainability Science and Engineering (Elsevier, 2010), ch. 6.

[3] A. Cipollina, G. Micale, Sustainable energy from salinity gradients (Elsevier, 2016).

[4] F.G. Bănică, Chemical sensors and biosensors: fundamentals and applications (John Wiley \& Sons, Ltd, Chichester, 2012).

[5] J. Malmivuo, R. Plonsey, Bioelectromagnetis: principles and applications of bioelectric and biomagnetic fields (Oxford University Press, 1995).

[6] M. Tagliazucchi, I. Szleifer, Mater. Today, 18, 131 (2015). DOI: 10.1016/j.mattod.2014.10.020

[7] А.Б. Ярославцев, Рос. нанотехнологии, 7 (9-10), 8 (2012). [Пер. версия: 10.1134/S1995078012050175].

[8] A.S. Pshenova, A.I. Sidorov, T.V. Antropova, A.V. Nashchekin, Plasmonics, 14, 125 (2019). DOI: $10.1007 / \mathrm{s} 11468-018-0784-5$

[9] Б.Г. Ершов, В.И. Ролдугин, В.М. Рудой, П.А. Морозов, О.В. Дементьева, Коллоид. журн., 74 (6), 721 (2012). [Пер. версия: 10.1134/S1061933X12060063].

[10] X. Fan, I.M. White, Nature Photon., 5, 591 (2011). DOI: 10.1038/nphoton.2011.206

[11] L. Ermakova, M. Sidorova, T. Antropova, N. Jura, S. Lurie, Colloids Surf. A, 282-283, 279 (2006).

DOI: $10.1016 /$ j.colsurfa.2005.12.011

[12] A. Inayat, B. Reinhardt, J. Herwig, C. Küster, H. Uhlig, S. Krenkel, E. Raedlein, D. Enke, New J. Chem., 40, 4095 (2016). DOI: 10.1039/C5NJ03591K 
[13] A.S. Kuznetsova, L.E. Ermakova, I.N. Anfimova, T.V. Antropova, Glass Phys. Chem., 46, 290 (2020). DOI: $10.1134 / \mathrm{S} 1087659620030086$

[14] V.A. Kreisberg, T.V. Antropova, Micropor. Mesopor. Mater., 190, 128 (2014). DOI: 10.1016/j.micromeso.2014.02.002

[15] M.A. Girsova, G.F. Golovina, I.N. Anfimova, L.N. Kurilenko, Glass Phys. Chem., 44, 381 (2018). DOI: $10.1134 / \mathrm{S} 1087659618050061$

[16] В.А. Кочемировский, М.Ю. Скрипкин, Ю.С. Тверьянович, А.С. Мерещенко, А.О. Горбунов, М.С. Панов, И.И. Тумкин, С.В. Сафонов, Успехи химии, 84 (10), 1059 (2015). [Пер. версия: 10.1070/RCR4535].

[17] M. Sakamoto, M. Fujistuka, T. Majima, J. Photochem. Photobiol. C, 10, 33 (2009).

DOI: $10.1016 /$ j.jphotochemrev.2008.11.002 